\title{
Narración, identidad y \\ nación iraníes en la \\ República Islámica de Irán
}

\section{Alejandra González Guerrero*}

\section{Resumen}

T a identidad iraní se compone de diversos factores. La mayoría Lde los autores coinciden en cuatro: territorio, lengua, religión e historia. Como la idea de nación cambia y se adapta a los contextos, cada régimen exalta las características que más se acercan a su ideología. En la República Islámica, la religión se ha convertido en la más importante, pues esta se legitima al asegurar que solo su gobierno puede lograr que los asuntos terrenales estén en concordancia con la revelación; pero aún en el régimen, los discursos evolucionan y cada presidente ha tenido aproximaciones distintas a la idea de nación. La narración oficial de la nación también se va adaptando a los contextos y a las personas en el poder. La narración se difunde en diversos medios de comunicación, museos públicos, libros, discursos políticos y prácticamente cualquier espacio de comunicación oficial. Por ello, el Estado se asume con el monopolio de la narración, pues, además, ayuda a delinear la idea de nación que se pretende desde el poder. Esto es porque la interpretación de la idea de nación es fundamental para dar a Irán el lugar que creen debe tener no solo en el mundo ni frente a otras naciones, sino para explicar y explicarse qué es Irán.

\footnotetext{
Estudiante de doctorado en Ciencias Políticas con orientación en Ciencia Política, en la Facultad de Ciencias Políticas y Sociales de la Universidad Nacional Autónoma de México y Maestra en Estudios de Asia y África con especialidad en Medio Oriente en El Colegio de México. Contacto: aleglgr@gmail.com ORCID: https://orcid.org/0000-0002-4293-6152
} 


\title{
Palabras clave \\ Nación, identidad, narración, Irán, República Islámica.
}

Fecha de recepción:

marzo de 2021
Fecha de aceptacion:

junio de 2021

\section{Iranian Narration, Identity and Nation in the Islamic Republic of Iran}

\author{
Keywords \\ Nation, Identity, Narration, Iran, Islamic Republic.
}

\begin{abstract}
:
Many factors comprise Iranian identity. Most of the authors agree on four: territory, language, religion, and history. As the idea of the nation changes and adapts to the contexts, each regime exalts the characteristics that most closely match its ideology. In the Islamic Republic, religion has become the most important since it is legitimized by ensuring that only its government can make earthly affairs by revelation. However, the governmental speeches evolve, and each president has had different approaches to the idea of Nation. The official narrative of the Nation is also adapting to the contexts and the people in power. The narration disseminates through various media, public museums, books, political speeches, and practically any official communication space. That is why the State assumes a monopoly of narratives because it traces an idea of Nation according to the government's intention. The latter, because the notion of Nation is critical to give Iran the place in which they believe it should have, not only in the world or in front of other nations but to explain what Iran is.
\end{abstract}

\section{Introducción}

Es imposible determinar las razones absolutas e inamovibles por las que se logra la cohesión en torno a la identidad iraní. Sin embargo, la literatura coincide en cuatro elementos: historia, lengua, territorio y religión. La justificación política del régimen en turno 
siempre ha estado relacionado con uno o varios de estos elementos y la exaltación de alguno sobre el resto ha sido una constante en los discursos del régimen y/o de las personas en el poder.

La República Islámica de Irán (RII) suele poner la religión como prioridad en la identidad, pues en ella basa su ideología, en parte porque: "Mientras que el mismo Cristo afirma que solo le preocupa el espíritu y no le interesan los asuntos físicos, ni el gobierno, ni la política; el Islam exige el gregarismo y la alianza, y se ocupa de todos los asuntos sociales humanos sin excepción" (Tabatabai, 2016, p. 210).

El Islam se ocupa de la vida espiritual y regula cómo las personas musulmanas se desarrollan en la vida mundana. Basado en esta afirmación, el gobierno de la RII trata de justificarse a sí mismo mediante la regulación de los asuntos terrenales para lograr la concordancia con las pretensiones religiosas.

La política se ha convertido en una de las mayores preocupaciones de muchas sociedades musulmanas, pues: "Es ampliamente declarado y creído tanto por musulmanes cuanto por no musulmanes que el Islam y la política están estrecha e inevitablemente entrelazados sino es que son inseparables en prácticamente todos los ámbitos y que esto ha sido cierto desde el surgimiento del Islam hasta el presente" (Keddie,1995, p. 220).

El profeta fue líder religioso y líder político de su comunidad. Gran parte de su revelación se enfoca en la acción política, cómo gobernar y cómo asumir un buen gobierno o combatir uno malo. Bajo esta premisa, la RII ha pretendido gobernar y legitimarse en el poder, pues hacen una interpretación política de la revelación para justificar que el gobierno apropiado para Irán es islámico e iraní, pues cumplen con dos principios muy importantes desde la conversión, cuando "los iraníes se volvieron musulmanes, pero permanecieron iraníes" (Meskoob, 2015, p. 43).

Entonces, el régimen de la RII — desde el nombre- es islámico y es iraní. En teoría, abarca la mitad de las características mencionadas, pero hablar aisladamente de estas cuatro resultaría infructuoso, ya que ninguna identidad puede basarse en una fórmula, ni permanece sobre las únicas bases que la teoría ha señala- 
do. Por estas razones, para descifrar lo que en Irán se ha entendido como Nación, primero deben abordarse los argumentos que se han construido para justificar a la nación iraní.

\section{Iranidad}

La justificación que se da para la existencia de la nación es fundamental para poder imaginar a una nación, aunque se sabe que no es del todo real, ni precisa. A pesar de la artificialidad de esto, Nikkie Keddie (1995) apunta que:

En relación con el Medio Oriente, se puede decir que el nacionalismo iraní fue el menos 'artificial' de todos los nacionalismos del Medio Oriente, ya que se remonta a los grandes imperios preislámicos iraníes, principalmente a través de la versión escrita de la epopeya persa, el Shahnameh, que fue ampliamente conocido y recitado por analfabetos (p. 61-62).

Por lo tanto, la idea de Irán como una nación milenaria se basa, como casi todas, en tiempos inmemoriales y se apoya en los vestigios arqueológicos que, como se abunda más adelante, hacen creer que ha habido una constante en la identidad. La narración iraní se ha encargado de reproducir una historia continua, por lo menos desde los aqueménidas hasta hoy, es decir, "el objetivo de la intelectualidad iraní era restaurar el 'pasado glorioso de Irán' imaginado, supuestamente denigrado después de siglos de dominación árabe-islámica, y reunir a un país imaginado, que nunca había existido" (Mohammadpour \& Soleimani, 2020, p. 3). La narración de la nación iraní imaginó una comunidad que nunca ha existido y en la actualidad continúa la pretensión de imaginar que esta comunidad es homogénea y cohesionada a los principios oficiales.

Estos principios, como en casi todas las naciones del mundo, se relacionan con la adherencia a la tierra, puesto que no es casual nacer en ese lugar, ya que este hecho se justifica por medio de algún linaje o significado social y personal. Esto es, "La tierra natal 
en el sentido de residencia de una vida verdadera y una existencia espiritual, no se trata de este u otro territorio porque la tierra en sí también se convierte en poseída por verdad y calidad en su relación con el cielo" (Meskoob, 2015, p. 43).

El lugar de nacimiento y residencia es importante para cada persona porque cuenta parte de su historia y, si es el caso, también de la historia familiar, entonces deja de ser solo un sitio, para convertirse en un lugar cargado de Historia, historias, emociones e ideas. Las personas que lo habitan se relacionan con él y con el resto de los residentes. Además, pueden convertirse en comunidad.

Irán, por supuesto, no es la excepción a esta dinámica y, ayudada por la narración nacional, exalta la adherencia a una tierra milenaria con historia antigua y que desde tiempos inmemoriales ha sido trascendente para la historia mundial, con grandes momentos y personajes que son parte de la memoria colectiva en gran parte del mundo.

Algo similar ocurre con la lengua persa que, a pesar de que no es homogénea para toda la población, es un símbolo del nacionalismo oficial, cuyo uso está expandido en la región, pues tiene enorme influencia en las lenguas de los lugares conquistados por los otrora grandes imperios que se originaron en lo que ahora es Irán. Además, es importante mencionar su relación con la religión, pues, entre otras razones, "la aceptación del persa como segunda lengua del Islam, le trajo cierto grado de santidad" (Banuazizi, 2015, p. 11). La lengua persa se ha relacionado con la religión y la llamada "alta cultura" en el Medio Oriente desde que el Islam llegó a estas tierras.

La religión tiene gran importancia en Irán, no solo política, sino social. La mayoría de la población practica el shiísmo duodecimano, pero hay otros credos enaltecidos por la narración por haber estado presentes desde los tiempos inmemoriales y que los discursos presumen aceptados. Entre estos credos se pueden mencionar al zoroastrismo, al judaísmo y al cristianismo, los cuales están reconocidos en la actual Constitución iraní —existen también otras minorías religiosas no reconocidas por el Estado islámico, como los musulmanes suníes-. Sin embargo, las políticas 
y la realidad exaltan la preponderancia de la religión mayoritaria, en especial en la RII, ya que "las formas modernas de avivamiento o 'islamismo' afirman que el mensaje original, en su sentido puro, es recuperable” (Soleimani, 2017, p. 2).

Como ya se mencionó, el régimen asume y presume hablar en nombre del verdadero Islam, ir a las fuentes y traerlo al presente; por ello es que "como aclaró Jomeini, se trataba de leyes divinas que no podían alterarse y a las que todo el mundo estaba sujeto [...] Jomeini parecía estar sugiriendo que la ley islámica protegía a las personas de un gobierno arbitrario" (Ansari, 2012, p. 196). La RII se ha apropiado de la religión mayoritaria y ha impuesto su interpretación del ideal de la cotidianidad para toda la población.

\section{Religión y Religiosidad Oficial en la República Islámica}

La fusión entre la religión y la RII comenzó desde la Revolución, pues esta se usó como bandera para contrarrestar las políticas que se interpretaron como antireligiosas de Pahlavi; además de que el líder de la revolución era un religioso que supo usar su posición y “aunque Jomeini no afirmó ser el último imán que regresó como Mahdi, a quien esperan los shiíes duodecimanos, su llamamiento tuvo un efecto mesiánico y algunos seguidores pensaban en él en términos mesiánicos" (Keddie, 1995, p. 169).

Por otro lado, inspirado por el "[...] matrimonio del Islam shií y el método marxista que Shariati trató de promover [y que] resultó ser una mezcla ideológica muy potente para una generación de jóvenes iraníes cada vez más educados y ansiosos por adherirse a una ideología que parecía moderna pero arraigada tradicionalmente" (Ansari, 2012, p. 189).

Jomeini cruzó los principales intereses de las personas ante la inminente presencia del capitalismo y el imperialismo occidental en Irán, con las enseñanzas religiosas. En otras palabras, justificó el rechazo a las políticas de Pahlavi mediante interpretaciones de la revelación y otras fuentes islámicas. Este rechazo se debía a que, según Jomeini (2002), “el único gobierno que la razón acepta como legítimo y acoge libre y felizmente es el gobierno de Dios” (p. 170), 
mientras que el régimen Pahlavi, aunque no renegó de la religión, fue muy laxo e incluso contrario a los principios islámicos.

En respuesta a ello, por un lado, exaltaron el rechazo a la monarquía, puesto que "el Islam, entonces, no reconoce la monarquía. La herencia o sucesión no tienen lugar en el Islam” (Jomeini, 2002, p. 31) y, por el otro, impulsaron la radicalización de los grupos conservadores que deseaban un régimen religioso o, al menos, guiado por los principios islámicos. En palabras de Jomeini (2002), "No decimos que el gobierno deba estar en manos del faqih [jurisconsulto]; más bien decimos que el gobierno debe funcionar de acuerdo con la ley de Dios, por el bienestar del país y del pueblo exige esto, y no es factible excepto con la supervisión de los líderes religiosos" (p. 170)

Esto significa que, como sería completamente irracional ir en contra de los designios de Dios, justificó la Revolución y la posterior República Islámica por la necesidad de que las leyes mundanas se basaran en las religiosas para así lograr la armonía y bienestar del país, y de la población, es decir, el orden divino.

Bajo este mismo principio, "el Estado-nación moderno se convierte en la medida de releer la historia musulmana del gobierno" (Soleimani, 2017, p. 2); el gobierno es quien escribe su Historia y adapta la narración a las necesidades e intenciones del momento o de los líderes en turno. Entonces, "el Estado-nación moderno gestiona, repiensa, redefine e incorpora o descarta selectivamente aspectos de la religión constantemente" (Soleimani, 2017, p. 4), el régimen de la RII se asume con el monopolio de la interpretación de la revelación islámica y se ha apropiado de los medios para la difusión de su versión de la religión como única válida.

Este pretendido monopolio también está en las formas de entender el nacionalismo y sus aproximaciones a él, pues al inicio de la República, Jomeini rechazó y repudió el nacionalismo porque iba en contra de la unidad islámica, y la pretendida ummah [comunidad musulamana], pero poco tiempo después —en especial durante la guerra contra Iraq (1980-1988) — entendió su importancia y lo adaptó a la nueva ideología. Por lo que, aunque “ideológicamente, el nacionalismo iraní parecería contradecir la 
plataforma de la República Islámica, el régimen posrevolucionario también debió tener en cuenta los intereses nacionales de Irán al configurar su política” (Zimmt, 2017, p. 136).

La RII no adoptó, ni reprodujo el nacionalismo como se venía desarrollando desde los Qayar, sino que seleccionó lo que se acomodaba a sus deseos e intereses, y lo adaptó a sus discursos. Entonces, a pesar de que "Jomeini era especialmente cauteloso con el nacionalismo en el período inmediatamente posterior a la victoria de la revolución porque el tipo particular de nacionalismo que había adoptado el Sha era, en muchas formas, contradictorio a la ideología de la revolución y porque el período posrevolucionario exigió una ruptura decisiva con el régimen anterior" (Samuel, 2017, p. 258).

La RII adoptó el nacionalismo como fuerza para impulsar la cohesión necesaria para sobrevivir a una revolución y una guerra, ya que "los líderes de la República Islámica de Irán encontraron el nacionalismo no solo útil, sino atractivo” (Ansari, 2012, p. 232), los líderes entendieron que el nacionalismo no era únicamente lo que los Pahlavi habían planteado, sino una forma de unirse y exaltar la identidad iraní, sin que esto significara el rechazo a la identidad islámica. La República Islámica logró tejer la religión islámica con el nacionalismo iraní y, hasta el presente, este tejido sigue siendo una relación exitosa en Irán.

Uno de los primeros grandes hitos en el devenir de la idea de iranidad fue la conversión religiosa, pues el Islam se asume como una religión que hermana a todas las personas adscritas a ella. La ummah se convierte en la principal comunidad de los creyentes, ya que "el Islam se declaró como la creencia de la hermandad. Lo principal era la fe y lo que diferenciaba era ser creyente o no, no si era árabe, persa, turco o tayiko" (Meskoob, 2015, p. 96). Como ya he mencionado, los iraníes se convirtieron al Islam y se volvieron parte de la ummah, pero permanecieron iraníes al conservar su historia anterior y exaltar sus aportaciones a la religión. Este hecho tampoco es monocausal, a pesar de que se ha tratado de señalar algunas razones como únicas, por ejemplo, Meskoob (2015) asegura que "mantuvimos una nacionalidad o, mejor dicho, nuestra identidad nacional, nuestra iranidad, mediante la bendición 
de la lengua, por medio de la vitalidad del persa como un refugio. A pesar de la fragmentación política en numerosas unidades geográficas y con gobiernos árabes, iraníes y túrquicos" (p. 29).

La lengua es un componente importante de la identidad iraní pero no es universal, pues no es la lengua materna de toda la población, ni la única razón para creer que existe esta identidad ni la única justificación para mantener la idea de comunidad separada de otros componentes de la identidad política, social y religiosa.

La lengua es uno de los principales rasgos de la identidad iraní, pues es fundamental para la narración y es una herramienta, consecuencia y razón de la persocentralidad. Todo esto se debe a que "la lengua es el más esencial y más común medio de comunicación en la vida diaria y el medio más apropiado para traer a la existencia y dar forma a ideas, y también para describir y explicar emociones" (Meskoob, 2015, p. 37). La lengua es la forma de comunicarnos, otorga identidad y semejanza con las personas a nuestro alrededor, nos permite hacer comunidad y distingue a un grupo, pues influye en el pensamiento. Por lo tanto, "la lengua es el mejor, pero no el único, medio para dar forma a una nación o gente. Artes y otros factores sociales, y culturales suelen acompañarla" (Meskoob, 2015, p. 37). La lengua es parte del desarrollo de la vida cotidiana y de los eventos extraordinarios; de ella parten todas o casi todas las expresiones y comunicaciones. Por ello su centralidad en las políticas de homogenización y en las herramientas de difusión de la idea oficial de nación.

\section{Política y nación}

La RII se ha legitimado a partir de la afirmación de que "la religión y los valores religiosos no se pueden imponer, solo se pueden cultivar desde el individuo hacia arriba y, en consecuencia, "si una sociedad es religiosa, su gobierno también adquirirá un tono religioso"' (Ansari, 2012, p. 241); en consecuencia, han tratado de demostrar que son, no solo los poseedores de la interpretación correcta de la revelación, sino las personas correctas para guiar a la Nación iraní y que son herederos de una larga tradición religiosa, 
y enfatizan la importancia de la Revolución en el devenir de la Historia nacional.

El siglo XX fue convulso en Irán, pues vivieron varios movimientos sociales, dos de esos levantamientos, la llamada revolución constitucional de 1905-11 y la 'Revolución Islámica' de 1978-79 fueron grandes movimientos populares que cambiaron la forma de gobierno y duraron más de un año. Otros dos movimientos, el movimiento de las Protestas del Tabaco de 189192 y el movimiento de nacionalización del petróleo de 1951-53, involucraron de manera similar a grandes masas de personas en varias ciudades y resultaron en victorias al menos temporales, en ambos casos principalmente contra empresas británicas, pero con implicaciones más amplias (Keddie, 1995, p. 73).

Esto, sin mencionar el cambio de dinastía Qayar a Pahlavi, pues esta fue mucho menos violenta y no involucró grandes movimientos sociales.

La RII resalta el hecho de que se haya tratado de una revolución en el amplio sentido de la palabra, pues cambió radicalmente el gobierno, derrocó y exilió a los anteriores líderes, cambió políticamente las formas del gobierno, su relación con la sociedad y hasta cómo se relaciona la sociedad con el gobierno. Por ello, "parece haber pocas dudas de que la revolución iraní de 1978-79 fue una revolución, principalmente política, ideológicamente y debido a su participación civil masiva" (Keddie,1995, p. 2). La RII se asume portadora de los deseos y apoyo popular por conjugar la religión mayoritaria (y asumir su monopolio), y por ser los representantes en el poder de los deseos de los iraníes; pero también han tenido cambios y evoluciones en el discurso, algunos como consecuencia del contexto nacional, regional o internacional, otros por deseos o exigencias de la población.

La evolución de la forma de aproximarse a la idea de nación se puede identificar en los discursos y políticas de los presidentes, especialmente después del fin de la guerra contra Iraq y de la muerte de Jomeini (1989). Por ello es que 
[...] era cierto que tanto Rafsanyaní cuanto Jatamí habían intentado explotar sentimiento nacionalista, pero cada uno de ellos había abordado la cuestión de manera tentativa y, a menudo, con una fuerte cualificación. En el caso de Jatamí, el enfoque fue de inclusión, con el objetivo de empoderar a las masas. Ahmadinejad, sin embargo, pareció lanzarse sin miedo y no solo adoptó un enfoque mucho más inequívoco, sino que buscó vincularlo a su persona en una narrativa renovada del 'salvador', que también buscó sacralizar asociándolo con la escatología shií (Ansari, 2012, p. 280).

Cada presidente ha tenido una forma distinta de aproximarse al nacionalismo y ha pretendido crear un vínculo con la población a partir de él: Rafsanyaní siguió la idea que se había explorado (y explotado) durante la guerra contra Iraq; Jatamí incluyó el pasado preislámico y buscó el diálogo de Irán con el mundo; Ahmadineyad fue mucho más osado al usar cada uno de los elementos que se le presentaron, desde exaltar la historia nacional, recurrir a la narración de tiempos inmemoriales, hasta usar las confrontaciones por la crisis nuclear; Ruhaní ha sido mucho más cauto y apostó por la reconciliación.

Sobre las posiciones de Jatamí y Ruhaní, es decir, sobre el diálogo y reconciliación, se debe hablar con mucha cautela, pues ha habido varios momentos en que las relaciones con potencias internacionales han terminado en intervención y dominación extranjera. En parte por esto, "la Revolución también fue nacionalista, expresando rechazo generalizado a la dominación extranjera. Además, los acontecimientos posteriores, ya sea el resurgimiento del descontento étnico y, en particular, la guerra contra Iraq, mostraron la vitalidad del nacionalismo" (Litvak, 2017, p. 3). El descontento social con el gobierno de Reza Pahlavi estuvo relacionado con la intervención extranjera y la forma en que este permitió que gobiernos extranjeros intervinieran en las políticas nacionales.

El rechazo a las otras formas de gobierno y regímenes monárquicos anteriores también se debió a que permitieron la interven- 
ción extranjera, por lo que "los iraníes responsabilizaron a su gobierno de las depredaciones occidentales en 1891, en la revolución constitucional de 1905-11, la nacionalización petrolera de 195153 bajo Mosaddeq, las manifestaciones de 1963 en torno a Jomeini y la revolución de 1978-79" (Keddie, 1995, p. 101) entonces, en Irán sigue habiendo un rechazo generalizado por las intervenciones extranjeras en cualquier aspecto, pues se reconocen como una nación milenaria con la Historia e importancia suficiente como para repudiar que potencias extranjeras se asuman superiores y decidan su devenir.

Una forma de hacer comunidad a una nación es, sin duda, la posibilidad de crear y moldear el nacionalismo y, en Irán, las distintas aproximaciones políticas al nacionalismo lo han hecho preponderante en la definición de la identidad iraní, pero sigue teniendo diversas inconsitencias, pues la pretendida centralidad oficial se esfuerza por circunscribir su definición a unas cuantas características que convienen al régimen en turno e ignoran el contexto y a las diversidades.

Debido a esta centralidad, "el nacionalismo en todas sus manifestaciones ha sido el punto de referencia al que todas las ideologías en competencia han tenido que adherirse en última instancia, y dentro del cual la mayoría ha sido subsumido" (Ansari, 2012, p. 1). Entre ellas, la religión; pero no la creencia individual y acercamiento personal a la religión en sí, sino la forma colectiva de identificarse como creyentes dentro de las fronteras iraníes, ya que "en primer lugar, la religión no es externa al nacionalismo. Segundo, la religiosidad no es un significante étnico, o un subproducto cultural de la etnia. Tercero, la religión es central y no marginal en el caso del nacionalismo estudiado" (Aghaie \& Marashi, 2014, p. 184-185).

Como se ha explicado, la religión es parte de la identidad iraní y, por lo tanto, parte del nacionalismo. En cierta medida por estos deseos de poner a la religión al centro y, sobre todo, por la idea de nación y nacionalismo que Pahlavi trató de imponer, 
[...] después de la Revolución de 1979, Jomeini se pronunció contra el nacionalismo. En un discurso pronunciado el 12 de septiembre de 1980, arremetió contra el 'nacionalismo (qawmiyat va-meliyat), que crea odio y animosidad entre los musulmanes, los debilita y los divide' por estar 'contra los principios del Islam y los intereses de los musulmanes', y un truco de los 'extranjeros atormentados por el Islam y su inmenso ritmo de crecimiento en todo el mundo'. Sin embargo, aclaró que 'el amor a la patria y a los compatriotas, protección de las fronteras de un país son cuestiones que no se cuestionan"' (Grinberg, 2017, p. 208).

Al inicio de la República, cuando se comenzaban a realizar los cambios políticos e ideológicos que habían llevado al triunfo de la Revolución, entre otras razones, la ortodoxia obligada del discurso y los deseos de exportar la Revolución Islámica llevaron a Jomeini a renegar de la idea de la nación iraní diferenciada del resto de la ummah, pero la realidad del contexto le hizo revirar y llevaron a Jomeini aceptar el nacionalismo siempre que estuviera supeditado al Islam.

El nacionalismo en la República Islámica está siempre tejido con la religión y, como ya he repetido, se ha pretendido que el Islam - específicamente el shiísmo duodecimano - sea el más importante factor de la identidad iraní. Esta idea se ha repetido desde antes de que siquiera existiera un movimiento social en contra de la monarquía Pahlavi, ya que los que ahora se reconocen como ideólogos de la República Islámica-Morteza Motahhari, Mohammad Beheshti, Mehdi Bazargan y Alí Shariati- señalaron la importancia de la religión en la conformación de la identidad iraní e incluso la apuntaron como la más importante, pues "eran muy conscientes de su identidad como iraníes, pero a diferencia de los intelectuales seculares, consideraban al Islam como inseparable del iranismo" (Grinberg, 2017, p. 210). Estos intelectuales trataron de explicar la identidad iraní y se dieron cuenta de la importancia de cada uno de los elementos, pero obviaron las diversidades y los intereses en torno a la conformación de esta idea, y su uso en el nacionalismo. 
Ante la infinidad de posibilidades para definir una identidad y después de los intentos por pretender definir la i raní a partir del mito de la arianidad y la narración en torno a la fundación de Irán por los arios - Irán significa "la tierra de los arios”- - Es importante recordar que es imposible constreñir una identidad nacional a una raza, es absolutamente erróneo suponerlo. Las identidades se componen de diversos factores. Como ya se mencionó, los principales elementos de la identidad iraní — que no los únicos - son la historia, el territorio, la lengua y la religión.

Cada grupo se aproxima a ellos de forma distinta y la preponderancia discursiva de uno u otro tiene mucha más relación con el grupo que construye ese discurso que con las personas que lo reciben y, muchas veces, lo asumen. Es decir, cada grupo de poder tiene un enfoque e intereses distintos, entonces imaginan una nación, un nacionalismo y una identidad distinta donde enfatizan alguno de los factores mencionados. Esto no significa que en las personas que asumen y viven la identidad iraní sea igual. Cada persona aprende, entiende, se apropia y vive la identidad de manera distinta.

También es muy importante apuntar que no se trata de una identidad aislada que se ha construido sin conexión con el contexto, al contrario "la identidad nacional iraní - gracias a factores tales como los medios de comunicación, contactos internacionales y las posiciones de poderes exteriores - se ha entrelazado con lo que sucede fuera de Irán” (Banuazizi, 2015, p. 17). A pesar de lo que Nikkie Keddie (1995) define como antiextranjeros ( $\mathrm{p}$. 62), Irán no está aislado, sino que vive el contexto y se va adaptando a él. Un ejemplo perfecto de esta adaptación necesaria son los discursos de Jatamí que, por un lado, vio a la identidad iraní como inexorablemente conectada con el Islam, pero sin negar la parte no islámica de la identidad.

Durante su gestión, en uno de sus discursos, "Jatami desafió tanto a los defensores de una identidad puramente preislámica como a aquellos que la niegan. En cambio, declaró que 'nuestra identidad es iraní-islámica"' (Aghaie \& Marashi, 2014, p. 266). 
Y, por otro, "Jatami llegó al poder cantando el lema de <diálogo entre civilizaciones>, que tenía como objetivo fundamental poner fin al aislamiento político de Irán. Tal énfasis en el diálogo con el mundo, sin darse cuenta, abrió un espacio limitado para el resurgimiento de culturas subalternas como el de los kurdos" (Mohammadpour \& Soleimani, 2020, p. 6-7).

Ambas posturas hablan de la inclusión que el presidente trató de impulsar, no solo por su forma de pensar, sino porque durante sus períodos presidenciales buscó una nueva forma de cohesionar a la población, pues ya no podían vivir del recuerdo, ni de la herencia de la Revolución, ni de la guerra. Jatamí llegó al poder como un triunfo de los sectores de la sociedad iraní que buscaba reformas a los modos anquilosados de la RII, ya en su encargo debió encontrar y reforzar las estrategias que lograran que la población continuara apoyando a la República Islámica.

En este orden de ideas, la identidad depende siempre de diversos factores, pero hay rasgos que se han ido resaltando y que pueden ayudan a definir la iranidad, Aghaie y Marashi (2014) mencionan que "nuestra nación (mellat) siempre es especialmente sensible a su identidad islámica e iraní, y han considerado que esta cuestión es importante. La identidad islámica e iraní es críticamente importante para nosotros" (p. 190). Pero es muy importante el énfasis en que son dos factores separados que se tejen y conviven como un tejido, aunque son dos factores y, de hecho, uno ayuda a construir al otro, es decir, la identidad iraní asume el componente islámico, pero desde el shiísmo duodecimano y con las características que Irán (y su historia) han aportado al Islam. Los iraníes son iraníes y además son musulmanes.

\section{Narración de la nación y República Islámica}

La conformación de la nación iraní es sumamente compleja y depende de muchos factores internos y externos. Es imposible pretender aislarla como una definición única, ni como una idea permanente, pues no solo va cambiando según el contexto, sino que la percepción de las personas que viven la identidad siempre será 
distinta del resto, ya que también depende del contexto personal, local, regional, nacional e internacional.

Escribir una narración que especifique quiénes somos y de dónde venimos abona a cierta estabilidad, aunque sea impostada y esta también mute. Tener una narración ayuda a las naciones a recordar quiénes son. La narración otorga el sentido a la identidad, pues le da coherencia al discurso y sentido histórico a la idea o sentimiento de nación.

Esto se debe a que "los procesos necesarios para la formación de la nación son la autodefinición, la creación de mitos y memorias, la territorialización, la cultura pública y la estandarización jurídica. De particular importancia en este sentido es la centralidad de los elementos simbólicos: mitos, recuerdos, tradiciones, valores, rituales y símbolos" (Litvak, 2017, p. 26). La narración está al centro de las necesidades de las identidades, pues es ella la que delinea la justificación de su existencia, ayuda a la autodefinición mediante la explicación de su pasado, sus mitos, sus memorias, la historia del territorio (actual e histórico). En resumen, la narración delinea la historia de la nación para que las personas que habitan el territorio y/o se adhieren a la identidad expliquen su origen y devenir.

La narración también se va adaptando a los cambios políticos y sociales, va olvidando eventos y recordando otros. La Historia de la Nación evoluciona con ella, pues el presente tiene implicaciones distintas al pasado, no solo en términos de regímenes, sino de contexto y desarrollo; pero no deja de estar centralizada, es decir, hay una narración oficial y es la que se cuenta en los libros de texto y en los medios de comunicación oficiales y aliados.

Aunque los medios de comunicación son las herramientas más comunes, no son las únicas usadas para la propagación de la narración y el discurso oficial. Los censos son parte importante, junto con los museos, pues es ahí donde el Estado exhibe de manera oficial y aparentemente objetiva la versión de nación que le interesa difundir. Por ello, "los museos sirvieron para exhibir el pasado de una manera que sería accesible para los plebeyos y útil para los especialistas, ya que proporcionaba 'hechos' que podían 
complementar y corregir textos que tendían a reflejar los sesgos del autor" (Ansari, 2012, p. 107).

Los museos parecen espacios inocuos donde solo se exhiben las piezas que forman la Historia nacional, unos aparentemente inocentes trozos físicos de Historia. Pero la selección, la curaduría, el orden y la coherencia que se les da, altera por completo la narración. Los museos hacen Historia y escriben la narración, por esta razón, en la actualidad el Museo Nacional (donde se exponen las piezas y se cuenta la Historia preislámica) es pequeño y demuestra poco interés del gobierno, mientras el Museo de la Defensa Sagrada es muchísimo más grande, con curaduría y discursos claros, con muchísimo más presupuesto. Esta comparación hace evidente cuál es el evento histórico que interesa exaltar al régimen.

Los museos pueden ser una fuente para la narración, igual que los mitos fundacionales y los mitos modernos, como los políticos. Según Ansari, en el Irán moderno, "los mitos políticos modernos, más que los históricos, llegaron a moldear la política de la nación en la era de los medios de comunicación" (Ansari, 2012, p. 288), pues exaltan las hazañas políticas que llevaron a Irán a ser la nación actual y son más moldeables a los discursos que los mitos históricos o fundacionales, pues los segundos son ya parte de la tradición y la memoria, y, por lo tanto, es muy difícil cambiar la idea que tiene la población sobre los mitos que la han formado.

En cambio, es posible adaptar la interpretación de los hechos recientes a los discursos o a la idea de nación del régimen en turno. Ejemplo de esto es el manejo oficial de la memoria de la Revolución Constitucional y del Shahnameh (Libro de los Reyes), pues la RII continúo con la negación (que inició con los Pahlavi) de la importancia de la Revolución Constitucional para exaltar la trascendencia de la Revolución Islámica y ha sido relativamente exitosa en este propósito; mientras que, al inicio de la República, trataron de diluir la presencia e importancia del Shahnameh, pero no solo no lo lograron, sino que terminaron incluyéndolo en los discursos oficiales. 
Esta lucha contra el Shahnameh tuvo varias etapas. Primero fueron ciertos ataques (y hasta repudio), después solo trataron de desvanecer su importancia y posteriormente fue su inclusión en los discursos. Es decir, "en el primer o segundo año después de la revolución, también dirigían algunos de sus ataques contra Ferdowsi. Cambiaron el nombre de la Universidad Ferdowsi en Mashhad y quitaron copias del Shahnameh de muchas librerías" (Banuazizi, 2015, p. 16).

Cambiar los nombres de instituciones, calles, ciudades es una acción muy común después de un cambio de régimen, pero pretender eliminar de la memoria nacional una de las principales fuentes que les recuerda su lugar en el mundo de las naciones, no solo es infructuoso, sino obtuso, pues quisieron borrar una de las más importantes fuentes (sino es que la más importantes) de la iranidad. El Corán es el libro que les trajo una invasión y los convirtió a una religión que aceptaron y adoptaron, pero el Shahnameh es el libro que les recuerda quiénes son y les ayudó a conservar su identidad preislámica.

Al final, "los mitos del Shahnameh [no] fueron eliminados por completo del discurso público, sino que desempeñaron un papel menos prominente en el discurso oficial y al mismo tiempo siguieron siendo importantes en los círculos literarios y de oposición" (Ansari, 2012, p. 116). Los esfuerzos fueron vanos y se dieron cuenta de que podría ser mucho más beneficioso apropiarse de la fuente y usarla en su favor, entonces, como los ideólogos del nacionalismo moderno, creyeron que "leer el Shahnameh inculcaría sentimientos positivos y un sentido de orgullo nacional, valentía y patriotismo entre los iraníes" (Ansari, 2012, p. 105).

La obra de Ferdowsi otorga identidad porque les separa del resto de las naciones e identidades de la región, describe quienes son y describe su origen y devenir. Es decir, el Shahnameh les da razones para sentir orgullo, puesto que demuestra que "el adjetivo iraní no estaba destinado a ser una distinción geográfica, sino que implicaba alusiones apenas disimuladas a la superioridad sobre la base no solo de una prioridad aparente sino también de una sofisticación cultural” (Ansari, 2012, p. 1). Los iraníes se asumen una 
cultura milenaria que ha abrevado a las culturas con las que han tenido contacto - ya sea por medio de conquistas de los iraníes o a los iraníes, o por intercambio- e incluso han aportado a su identidad, pero se distancian del resto, pues se cree que la iranidad implica sofisticación; de hecho, esta se ha señalado para separar a la identidad iraní de la árabe.

Aunque esta no es la única fuente de la narración, "Irán tuvo la suerte de tener un depósito de mitos —encapsulados dentro, aunque no limitado al Shabmaneh de Ferdowsi- mediante el cual la práctica virtuosa podría ser transmitida" (Ansari, 2012, p. 55). Irán sí tenía memoria de sí misma, y esa memoria forma parte de su vida cotidiana, pues recuerdan el Shahnameh constantemente para hablar de sí mismos y enorgullecerse; pero la modernidad impuesta y la necesidad de los regímenes de validarse en el mundo de las naciones (especialmente frente a Europa), les llevó a escribir narraciones con influencias extranjeras, según los modos de Occidente. Por esta razón comenzaron a escribir historias nacionales oficiales, pues asumieron que "no hay identidad nacional sin la formación de la memoria y la historia colectivas, [entonces] se dedicó un esfuerzo particular a las revistas históricas (más de 70), que tratan la historia iraní desde la antigüedad hasta el presente" (Litvak, 2017, p. 19). De nuevo, negaron la memoria y las historias colectivas que tenían desde hacía siglos para imponer una forma extranjera.

La influencia extranjera en la forma oficial de hacer memoria fue tal que las historias oficiales estaban basadas en fuentes occidentales que contaban la historia de Irán a partir de sí mismos, por lo que el Irán moderno se narró a sí mismo como una nación desde la otredad. Este hecho hizo que las historias de Irán fueran sumamente problemáticas, pues narraban un Irán ajeno al de la iranidad y que iba negando a las distintas identidades de la amalgama; por esto "los cientos de libros de historia, miles de artículos y documentales de televisión históricos han forjado una meta-narrativa de una historia iraní continua y bien integrada desde la antigüedad hasta el presente [pero ajena]" (Litvak, 2017, p. 19). 
La impostación de la narración con formas y fuentes extranjeras centralizó la redacción de la historia nacional y negó la posibilidad de diversidad o la inclusión de las otras identidades iraníes, es decir, acentuó la persocentralidad por medio del auto-orientalismo. Esto no significa que las identidades no persas (e incluso la persa) se circunscribieran a los discursos oficiales, sino que desde el Estado se hicieron esfuerzos por imponer una identidad e idea de persona iraní, pero estos no triunfaron y han encontrado resistencia en la población, especialmente en los grupos no persas.

Esta centralización hace que "los Estados consideren traición las narrativas alternativas (no oficiales)" (Soleimani \& Osmanza-deh, 2021, p. 3), pues incluyen eventos e interpretaciones distintas a la oficial y alteran la idea que se pretende imponer para entender e identificar a la Nación.

Probablemente, la narración sea uno de los factores de mayor interés para el monopolio oficial de las identidades, ya que su alteración puede cambiar el destino del régimen en turno o su idea de nación y ciudadanía que son fundamentales para que se mantenga en el poder. Por ello, "en Irán, las comunidades no persas no pueden cuestionar la narración soberana de 'lo nacional', histórico o religioso, mientras que los libros de texto están escritos para racializar el 'pasado' y el presente a expensas de esas comunidades” (Soleimani \& Osmanzadeh, 2021, p. 3).

El pretendido monopolio de la narración otorga un falso control sobre la idea de nación, pero es imposible tenerlo, pues cada grupo recuerda la historia según su percepción y posición en ella, por esto es que las comunidades no persas no se vuelven parte de la construcción de la narración y se encuentran en ella como elementos periféricos, a veces contingentes, que se han ido sumando a la idea central, es decir: según la narración, las comunidades no persas existen, pero se han ido homogeneizando según avanzó la modernidad y la islamización (o reislamización) de Irán.

Al triunfo de la Revolución, una de las primeras acciones fue la reescritura de la narración, pues "el mismo Jomeini era muy consciente de la necesidad de una narrativa adecuadamente grandiosa para enmarcar y este movimiento trascendental en la 
memoria colectiva, y consideró esto como una parte esencial del proceso revolucionario" (Ansari, 2012, p. 204). Contar la historia nacional a partir de los eventos y con la mirada del nuevo régimen sigue siendo muy importante para la RII, por ello se esfuerzan por mantener la versión única y centralizada de la narración, y evidentemente usaron al Islam como eje central de esta nueva versión.

Basado en la afirmación de que "el Islam es una religión de quienes luchan por la verdad y la justicia, de quienes claman por la libertad y la independencia; es la escuela de quienes luchan contra el colonialismo" (Jomeini, 1985, p. 1), Jomeini aseguró que el establecimiento de la República Islámica significaría un retorno al verdadero Islam y lograrían expulsar a los invasores extranjeros para tener un gobierno nativo que respondiera a las necesidades de los iraníes inspirado por la religión; pues:

[...] el gobierno islámico está sujeto a la ley del Islam que viene no del pueblo ni de sus representantes, sino directamente de Allah y su divina voluntad. La ley del Corán, que no es otra cosa que la ley divina, constituye la esencia de cualquier gobierno islámico y gobierna infaliblemente a todos los individuos que for-man parte de ella (Jomeini, 1985, p. 7).

A partir de su interpretación, aseguraron que la islamización no era más que obediencia a los designios divinos, pues la potestad sobre el poder político era dada por Dios y ello les permitiría lograr que la vida mundana correspondiera a las expectativas y a las leyes religiosas, pero también fue un pretexto para imponer cambios políticos y sociales que beneficiaran a los grupos cercanos al poder.

Después del triunfo de la Revolución, la narración islámica se concentró en recordar los sacrificios que se necesitaron para lograr llevar al poder al grupo que representa los verdaderos intereses del pueblo iraní y que son los únicos capaces de responder a sus necesidades. Por lo tanto, "la narrativa oficial de la República Islámica, esbozada arriba, que buscaba articular una historia narrativa de la resistencia popular musulmana iraní, ayudada e instigada por 
clérigos desinteresados, fue un mito de la salvación nacional por medio del Islam” (Ansari, 2012, p. 222).

El Islam salvó a Irán de la decadencia y la Revolución Islámica se enmarca como el momento cumbre de las movilizaciones sociales en el país y se señala como el evento más trascendente para lograr la nación que los iraníes necesitaban y merecían. Fue así como "la Revolución Islámica pronto se interpretó como la tercera gran revolución después de la francesa y la rusa” (Ansari, 2012, p. 201), y se adjudicó trascendencias nacionales, regionales y mundiales. Los líderes de la Revolución se han encargado de insertarla en la Historia nacional como el momento más importante en el devenir moderno y la ligaron con el resto de movimientos sociales que ocurrieron en el país durante el siglo XX. Esta narración de la historia de Irán a partir de los movimientos sociales:

...no implicó la imposición de una nueva narrativa, sino la reinterpretación de la antigua comenzando con la Revuelta del Tabaco, pasando por la Revolución Constitucional, la Crisis de la Nacionalización del Petróleo y, finalmente, la Revolución Islámica, insertando en el camino la importancia del levantamiento contra la Revolución Blanca — considerada como el momento fundacional de la revolución islámica - y selectivamente disminuyendo o descartando a aquellas personalidades que complicaron una narrativa limpia de ascenso (Ansari, 2012, p. 204).

La escritura de la narración de la República Islámica retomó momentos importantes que sirvieron para unir a la sociedad en torno a causas comunes, siguieron con la narrativa de continuidad en los movimientos sociales contra gobiernos injustos y se colocaron como la cima de estos.

De la misma forma que los gobiernos anteriores, la RII justificó sus discursos con una narración que contaba una historia ad hoc a sus pretensiones y adaptaron la memoria a estas. Aunque trataron de exaltar la islamización como el momento más importante en la historia, poco a poco fueron incorporando la época preislámica a la narración nacional. 
Los tiempos inmemoriales son el momento en que se asegura se fundó la nación y a partir del cual ha habido una historia ininterrumpida, son fundamentales para crear cohesión, identidad y exaltar el orgullo. La importancia que se da a los tiempos inmemoriales en Irán se basa en el reconocimiento internacional, pues varios personajes son trascendentes en la llamada Historia Universal. Aunado a esto, es sustancial señalar que "Irán era rico en evidencia arqueológica y debería usarla” (Ansari, 2012, p. 107), pues no solo se trataba de historias o menciones en las memorias ajenas, sino que el país contaba con basto legado arqueológico que recuerda el pasado y enaltece su importancia.

La presencia de esta valiosa herencia cultural material añade certezas a las afirmaciones de continuidad desde la fundación, pues hace parecer que el poder y la cultura pasaron ininterrumpidamente de civilización a civilización y que cada una estuvo ligada a la anterior. Por lo tanto, "la longevidad del Estado iraní fue fundamental para dar forma a una cultura política compartida e incluso a una memoria colectiva, al menos entre varios grupos de élite" (Litvak, 2017, p. 27). Esta creencia en la continuidad abona al orgullo nacional que se funda en un pasado glorioso y en la majestuosidad de su historia. La narración iraní resalta su grandioso pasado y lo justifica con su basto legado arqueológico.

Como se ha evidenciado, cada presidente tiene una forma particular de usar los discursos y reescribir la narración según sus ideas, ideales e intereses, entonces pese a que:

Rafsanyaní pudo haber visitado las ruinas de Persépolis y Jata-mí reflexionar sobre la ética del Shahnameh, Ahmadinejad [pre-tendió explotar descaradamente el sentimiento nacionalista] se deshizo de la precaución y se fue directo al corazón, alabando a los iraníes por su excepcionalismo y su genio muy particular, que estaba constreñido solo por la perfidia de los extranjeros (Ansari, 2012, p. 260).

Puesto que después de 25 años del triunfo de la Revolución y más de 15 años de la muerte de Jomeini —sin mencionar los 
eventos propios de sus períodos en el ejecutivo-, Ahmadineyad tuvo que buscar nuevas formas de cohesionar a la población y exaltar el orgullo nacional, por ello decidió recurrir a un período de la historia nacional del que la mayoría de la población tiene memoria y se siente orgullosa. En consecuencia, "Ahmadineyad fue el primer líder posrevolucionario en explotar plenamente la herencia aqueménida y alabar, en términos que pueden haber he-cho sonrojar a Mohammad Reza Shah, los logros históricos de Ciro el Grande" (Ansari, 2012, p. 278). Ahmadineyad encontró en los tiempos preislámicos un pretexto para aludir al nacionalis-mo, pues era una fórmula que se había usado en el pasado y sabía que podía resultar exitosa.

\section{La Idea de Nación Islamizada}

La idea de nación es la forma en que se interpreta a la nación, es decir, como los iraníes se apropian los discursos, la narración y crean su propio concepto. Parte fundamental de esta interpre-tación es dar a Irán el lugar que creen debe tener no solo en el mundo ni frente a otras naciones, sino para explicar y explicarse qué es Irán. De estos esfuerzos surgen nociones como "Irán no es una sola geografía, una nación, un pueblo, o una tribu; más bien es una escuela de pensamiento y un camino" (Aghaie \& Marashi, 2014, p. 192). Estas descripciones tratan de justificar la idea de una gran nación, pues no solo se trata de una historia o una narración, sino de un conjunto de factores que la hacen más grande que la "asible" nación.

Con la RII, además, se sumó la necesidad de llevar el verda-dero Islam y, aunque nunca han tenido intervenciones militares directas, sí han apoyado causas afines a sus intereses ya sea para legitimarse (como Palestina) o para afianzar su influencia en la región (como Siria). Entonces, a partir de afirmaciones como: "no es sólo nuestro deber en Irán, sino que también es el deber de todos los musulmanes del mundo, en todos los países musulmanes, llevar la evolución política islámica a su victoria final" (Jomeini, 1985, p. 2), han propaga- 
do la idea de que Irán debe defender y difundir la forma de vida del verdadero Islam que es la república islámica. No tratan de conquistar nuevos territorios, ni volver al "Gran Irán", sino que usan el discurso de la propagación del ver-dadero Islam y su influencia en la región para consolidar su idea de nación, es decir, usan como pretexto la fuerza en el exterior para afirmar y presumir que esa es la manera en que se debe vivir el Islam y entender la política.

Una parte fundamental de la idea o sentimiento de nación es que evoluciona, es decir, que :

“[...] este 'sentimiento de nación', ha cambiado a través de la historia. Nunca ha sido un único Estado ni ha tenido un único significado. No fue un único Estado porque fluctúa en intensidad. A veces ha estado sumamente presente en la etapa histórica o ha sido instrumental en la formación y edificación de la Historia, mientras en otros tiempos ha estado atado como una sombra en las alas, esperando redescubrir" (Meskoob, 2015, p. 173).

Como ya he mencionado, la idea de nación va cambiando para adaptarse al contexto y la idea oficial se adapta también a los deseos del régimen y los gobernantes en turno.

\section{Reflexiones finales}

La cohesión en torno a la nación no es asible ni monolítica, por ello se recuerda constantemente en los discursos y en pequeños guiños cotidianos. La versión oficial de la nación en la República Islámica de Irán es justamente islámica e iraní, es decir, ensalza la religión como el factor más importante de la identidad nacional, pero no olvida que es iraní y por tanto, aunque parte de la ummah, se distancian del resto de los países musulmanes y/o islámicos.

La larga historia iraní y las diversas fuentes artísticas, arqueológicas, la literatura y la memoria popular acentúan la idea de Irán como una gran nación, además de su influencia en la región, en las historias nacionales de diversos países y hasta en el devenir del Islam. Por ello, el cambio de país musulmán a país islámico, no 
cambió del todo la narración y se continuó la exaltación de los tiempos inmemoriales, aunque adaptados a las necesidades y deseos del nuevo régimen.

La narración nacional de Irán en la República Islámica recuerda que Irán permaneció iraní, aunque se convirtió al Islam.

\section{Referencias}

Aghaie, K. S., \& Marashi, A. (2014). Rethinking Iranian Nationalism and Modernity. University of Texas Press.

Ansari, A. M. (2012). The politics of nationalism in modern Iran. Cambridge University Press.

Banuazizi (2015) Foreword en Meskoob, S. Iranian national identity and the Persian language, Mage Publishers.

Grinberg. (2017). Pre-revolutionary Islamic discourse in Iran as nationalism: Islamism in Iran as nationalism en Litvak, M. (Ed.). Constructing Nationalism in Iran: From the Qajars to the Islamic Republic. Taylor \& Francis.

Jomeini, R. (2002). Islam and revolution. Routledge

Jomeini, R. (1985). The Little Green Book: Selected Fatawah and Saying of the Ayatollah Mosavi Khomeini. Bantam Books.

Keddie, N. (1995). Iran and the Muslim world: resistance and revolution. Macmillan.

Litvak, M. (Ed.). (2017). Constructing Nationalism in Iran: From the Qajars to the Islamic Republic. Taylor \& Francis.

Shahrokh, M. (2015). Iranian national identity and the Persian language, Mage Publishers.

Mohammadpour, A., \& Soleimani, K. (2020). 'Minoritisation'of the other: the Iranian ethno-theocratic state's assimilatory strategies. Postcolonial Studies.

Samuel, A. T. (2017) Guarding the nation: the Iranian revolutionary guards, nationalism and the Iran-Iraq War en Litvak, M. (Ed.). Constructing Nationalism in Iran: From the Qajars to the Islamic Republic. Taylor \& Francis. 
Soleimani, K. \& Osmanzadeh, D. (2021). Textualizing the Ethno-Religious Sovereign Nationalism, History, and Ethnicity in the Perso-Islamic Textbooks. Journal of the Association for the Study of Ethnicity and Nationalism. DOI: 10.1111/ nana.12705

Soleimani, K. (2017). Modern Islamic Political Thought, "Islamism" and Nationalism. Journal of Humanities and Cultural Studies R\&D. 2(1), 1-16

Tabatabai, M. (2020). Social Relations in Islam, [Kindle] Zimmt, R. (2017). Iranian nationalism, Islamic unity and Shi' ism in Iran's regional policy: from the Pahlavis to the Islamic Republic en Litvak, M. (Ed.) en Constructing Nationalism in Iran: From the Qajars to the Islamic Republic (Vol. 25). Taylor \& Francis. 